\title{
Clinical results of intensity-modulated radiotherapy for 250 patients with cervical and upper thoracic esophageal carcinoma
}

This article was published in the following Dove Press journal: Cancer Management and Research

\author{
Jiaqi Zhang \\ Wencheng Zhang \\ Baozhong Zhang \\ Dong Qian \\ Xiaoxia Li \\ Hualei Zhang \\ Qi Wang \\ Lujun Zhao \\ Qingsong Pang \\ Ping Wang
}

Tianjin Medical University Cancer Institute and Hospital, National Clinical Research Center for Cancer, Key Laboratory of Cancer Prevention and

Therapy, Tianjin's Clinical Research Center for Cancer, Tianjin 300060,

People's Republic of China
Correspondence: Ping Wang

Tianjin Medical University Cancer Institute and Hospital, Huanhu West Street, Tianjin 300060, People's Republic of China

Tel +86 $222334 \quad \mid 405$

Fax +86 222334 1405

Email wangping@tjmuch.com
Purpose: To evaluate and analyze the efficacy and prognostic factors of intensity-modulated radiotherapy in 250 patients with cervical and upper esophageal carcinoma.

Patients and methods: From September 2009 to September 2016, we retrospectively analyzed 250 patients with cervical and upper esophageal carcinoma treated with intensitymodulated radiotherapy (IMRT). In our study, all patients received IMRT, 54 patients with cervical esophageal carcinoma and 196 patients with upper esophageal carcinoma. Treatment response, survival status and failure modes of treatment were observed, and prognostic factors were analyzed.

Results: The median survival time was 22.60 months and 3-year survival rate was $42 \%$. The median progress-free survival time was 14.52 months and 3-year progress-free survival rate was $29.3 \%$. The median survival time and the median progress-free survival time for cervical esophageal carcinoma were 20.40 and 15.15 months, respectively. The median survival time and the median progress-free survival time for upper esophageal carcinoma were 25.80 and 14.52 months, respectively $(P>0.05)$. The significant clinical factors associated with survival were patient age, radiotherapy dose and T stages $(P<0.05)$. Radiotherapy dose and concurrent chemoradiotherapy were the significant clinical factors related to progression-free survival $(P<0.05)$. Recurrence appeared in $55.2 \%$ patients, including local recurrence in $22.40 \%$, region relapse in $10.40 \%$ and distant metastasis in $12.40 \%$. Local recurrence was the main mode of treatment failure. During treatment, the main treatment-related acute toxicity was leukocytopenia and anemia.

Conclusion: In this study, IMRT demonstrated clinical benefit and well-tolerated toxicity in patients with cervical and upper esophageal carcinoma.

Keywords: cervical esophageal carcinoma, upper esophageal carcinoma, intensitymodulated radiotherapy, prognosis

\section{Introduction}

Esophageal cancer is one of the most common tumors in the world and is characterized by invasive growth and poor prognosis. ${ }^{1}$ Cervical esophageal cancer accounts for $2-10 \%$ of esophageal cancer and upper thoracic esophageal cancer accounts for $5-10 \%$ of esophageal cancer. ${ }^{2,3}$ The recurrence rate of cervical and upper thoracic esophageal cancer is higher than that of esophageal cancer in the middle and lower thoracic segments. ${ }^{4,5}$ According to the American Joint Committee on Cancer/Union for International Cancer Control (UICC) 7th edition TNM staging criteria for esophageal cancer, cervical esophageal cancer is defined as that arising 
in the short segment range from the cricopharyngeus to the sternal notch, while the range of upper thoracic esophageal cancer is from the superior aperture of thorax to the lower edge of the arch of the azygos vein. Surgery is not the best treatment for cervical and upper thoracic esophageal cancer owing to the difficulty in surgical treatment and the high incidence of complications. ${ }^{6,7}$

Intensity-modulated radiotherapy (IMRT), a radiotherapeutic modality with high conformality and mild side effects, is often used for the treatment of cervical and upper thoracic esophageal cancer. Some studies demonstrate the advantages of IMRT in cervical esophageal cancer. ${ }^{8,9}$ However, few studies have investigated the outcomes of IMRT in patients with upper thoracic esophageal cancer, and the data regarding the clinical efficacy, failure patterns and prognostic factors for cervical and upper thoracic esophageal cancer patients treated with IMRT are still limited. Therefore, in this study, we retrospectively analyzed the data of 250 patients who had cervical and upper thoracic esophageal squamous cell carcinoma and treated by IMRT. The clinical efficacy and the associated prognostic factors were evaluated.

\section{Materials and methods}

\section{Patients}

We retrospectively reviewed patients who received treatment for histologically confirmed cervical and upper thoracic esophageal squamous cell carcinoma at the Cancer Hospital of Tianjin Medical University in the period 2009-2016. The eligibility criteria for this study were as follows: (1) patients with histologically confirmed esophageal squamous cell carcinoma; (2) cervical or upper thoracic esophageal cancer confirmed by chest x-ray, CT, gastrointestinal endoscopy, endoscopic ultrasonography or positron emission tomography-CT (PET-CT) and staged according to the 2002 UICC-TNM staging system, cervical esophageal cancer was defined as tumor arising in the short segment of esophagus between the cricopharyngeus and the sternal notch, and upper thoracic esophageal cancer was defined as the main tumor located between the superior aperture of thorax and the inferior margin of the azygos arch; (3) patients treated by IMRT and had not received surgical treatment; (4) no distant metastasis at the time of treatment and (5) no other critical illness affecting treatment. Patients who did not complete the radiotherapy plan were excluded.

\section{Treatment}

Radiotherapy

All patients received definitive IMRT. Patients were placed supine, fixed and underwent radiotherapy localization under enhanced CT with images obtained at 5-mm slice intervals. The target area delineation was performed according to the following criteria: (1) gross tumor volume (GTV) including primary tumors and radiographically identified metastatic lymph nodes, (2) clinical target volume (CTV) included the radiation field which was $3-5 \mathrm{~cm}$ beyond the GTV in all directions and the radiation field covered both peripheral subclinical lesions. In case of tumor invasion of the lower pharynx, skull base was considered the upper boundary of the CTV; the lower boundary of the CTV was $3 \mathrm{~cm}$ below the tumor or $1.5 \mathrm{~cm}$ below the carina, and (3) in order to eliminate placement error, the planned target volume (PTV) was $5 \mathrm{~mm}$ outside the CTV. Planning gross tumor volume (PGTV) was $5 \mathrm{~mm}$ outside the tumor and metastatic lymph nodes and $1 \mathrm{~cm}$ above and below the tumor. The radiotherapy plan was to achieve $95 \%$ coverage of the PTV by the prescribed dose. The median prescribed dose was $54 \mathrm{~Gy}$ (48-70 Gy) and 1.8 Gy daily 5 times a week. Patients who simultaneously received integrated boost IMRT had 60 Gy for $95 \%$ PGTV coverage. The target dose for normal tissue involved in the target area: average dose of both lungs $<13$ Gy, V $20 \% \leq 30 \%$, V $30 \% \leq 20 \%$; cardiac dose V $30 \leq 40 \%$, $\mathrm{V} 40 \leq 30 \%$; maximum spinal cord tolerance $<45 \mathrm{~Gy}$.

\section{Chemotherapy}

Neoadjuvant chemotherapy consisted of 1-6 cycles of paclitaxel taxol and cisplatin before radiotherapy. Concurrent chemotherapy was started during radiotherapy and lasted for 1-5 cycles based on the paclitaxel/docetaxel plus cisplatin. Adjuvant chemotherapy was started after the radiotherapy and consisted of 1-6 cycles.

\section{Follow-up evaluation}

The patients were evaluated for the clinical efficacy starting from 1 month after the end of treatment by endoscopy, chest CT, B-ultrasound, chest MRI and PET-CT. Patients were followed every 3 months during the first year after radiotherapy, every 6 months during the second year and annually after 3 years of treatment. The initial clinical response was evaluated after completion of IMRT according to the Response Evaluation Criteria for Solid Tumors (version 1.1) by chest CT scan, upper GI and ultrasound exam. ${ }^{10}$ The tumor progression after radiotherapy was divided into no progression, local progression, regional 
progression and distant metastasis. The local progression was defined as the recurrence of the primary tumor, the regional progression was defined as patients happened lymph node metastasis, the diagnosis of lymph node metastasis was as follows: lymph nodes were considered positive if they measured $\geq 1 \mathrm{~cm}$ on the short axis; roundshaped and if lymph nodes had clearly defined boundaries or exhibited an hypoechoic pattern, and the patients who had distant metastasis showed esophageal-derived tumor metastases. Acute toxic side effects during radiotherapy were graded by Common Terminology Criteria for Adverse Events v4.0.

\section{Statistical analysis}

Results were analyzed using SPSS version 22.0 (IBM Corporation, Armonk, NY, USA). The overall survival (OS) time was calculated starting from the date of initial treatment to the last follow-up or death time. The progression-free survival (PFS) time was defined as the time from the initial treatment to the first progression time or the last follow-up time. Kaplan-Meier analysis was used to calculate the OS rates and PFS rates. Log rank was performed to compare the survival differences between groups. Multivariate prognostic analysis was performed using Cox regression model. A value of $P \leq 0.05$ was considered statistically significant.

\section{Results}

\section{Patient characteristics}

A total of 250 patients (192 males and 58 females) qualified the inclusion criteria and were included in the analysis. These included 54 patients with cervical esophageal cancer and 196 patients with upper thoracic esophageal cancer. The characteristics of the patients are shown in Table 1. The median age was 61 years (range, 34-90 years). According to the UICC 8th edition TNM staging, most patients had stage IV disease. Sixty-five patients received neoadjuvant chemotherapy, 172 received concurrent chemotherapy and 106 received adjuvant chemotherapy.

\section{Treatment outcomes}

The follow-up rate was 99.2\%, 108 patients died during follow-up and the median follow-up time was 13.14 months (range, 1.04-56.71 months). The median OS was 22.60 months, and the 1-, 2- and 3-year survival rates were $74.4 \%, 49.2 \%$ and $42.0 \%$, respectively. The median PFS was 14.52 months, and the 1-, 2-, and 3-year PFS rates were 59.0\%, 34.7\% and 29.3\%, respectively (Figure 1). The median OS of patients with cervical esophageal cancer was 20.37 months. The 1-, 2- and 3-year survival rates were $75.2 \%, 46.4 \%$ and $38.7 \%$, respectively. The median PFS was 15.15 months and the 1-, 2- and 3-year PFS rates were $63.5 \%, 29.7 \%$ and $24.7 \%$, respectively.

The median OS of patients with upper thoracic esophageal cancer was 25.82 months. The 1-, 2- and 3-year survival rates were $74.2 \%, 50.1 \%$ and $41.1 \%$, respectively. The median PFS was 14.52 months, and the 1-, 2- and 3year PFS rates were $57.6 \%, 36.1 \%$ and $30.5 \%$, respectively. There was no significant difference with respect to survival rates and PFS rates between patients with cervical esophageal carcinoma and those with upper thoracic esophageal cancer $(P=0.76)$.

For esophageal lesion, after the initial response analysis, $185(73.9 \%)$ patients were presented with complete response (CR) and partial response (PR), 45 (17.9\%) patients with a stable disease (SD) and $20(8.2 \%)$ patients with progressive disease (PD).

According to Kaplan-Meier analysis, median OS of patients with GTV $\geq 32 \mathrm{~cm}^{3}$ (median value) and GTV $<32$ $\mathrm{cm}^{3}$ was 20.46 and 40.44 months $(P=0.046)$, respectively; the corresponding PFS was 10.94 and 16.70 months, respectively $(P=0.108)$. $\mathrm{CR}$ and $\mathrm{PR}$ were observed in 93 patients with GTV $\geq 32 \mathrm{~cm}^{3}$ and 92 patients with GTV $<32 \mathrm{~cm}^{3}(P>0.05)$. SD and PD were observed in 38 patients with GTV $\geq 32 \mathrm{~cm}^{3}$ and 27 patients with GTV $<32 \mathrm{~cm}^{3}(P>0.05)$.

Patients were categorized into 2 groups based on the radiation dose: $<60$ Gy $(28.2 \%)$ and $\geq 60$ Gy $(71.8 \%)$. The median OS in these 2 groups was 17.64 and 34.46 months, respectively $(P=0.002)$, while the median PFS was 10.94 and 17.28 months, respectively $(P=0.018)$. The median OS of patients who received $\geq 60$ Gy radiation dose was significantly higher than that of patients who received $<60 \mathrm{~Gy}$ radiation dose $(P<0.05)$; similarly, the difference between the median PFS of patients who received $\geq 60$ Gy and $<60$ Gy radiation dose was also statistically significant $(P<0.05)$ (Figure 2). $\mathrm{CR}$ and $\mathrm{PR}$ were observed in 150 patients with $\geq 60$ Gy and 35 patients with $<60$ Gy. SD and PD were observed in 35 patients with $\geq 60$ Gy and 30 patients with $<60$ Gy $(P<0.05)$.

The median OS of patients who received concurrent chemotherapy and those who did not receive concurrent chemotherapy was 30.62 and 18.60 months, respectively $(P=0.013)$; the corresponding PFS was 15.84 and 10.94 months, respectively $(P=0.039)$. $\mathrm{CR}$ and $\mathrm{PR}$ were observed 
Table I Clinical characteristics of 250 patients of cervical and upper esophageal carcinoma treated with intensity-modulated radiotherapy

\begin{tabular}{|c|c|c|c|}
\hline $\begin{array}{l}\text { Clinical } \\
\text { characteristics }\end{array}$ & $\begin{array}{l}\text { Number of } \\
\text { cases (\%) }\end{array}$ & $\begin{array}{l}\text { Cervical } \\
\text { segment }\end{array}$ & $\begin{array}{l}\text { Upper } \\
\text { thoracic } \\
\text { segment }\end{array}$ \\
\hline \multicolumn{4}{|l|}{ Sex } \\
\hline Male & 192 (76.8\%) & 39 (72.2\%) & I53 (78.I\%) \\
\hline Female & $58(23.2 \%)$ & 15 (27.8\%) & 43 (21.9\%) \\
\hline \multicolumn{4}{|l|}{ Age (years) } \\
\hline$\geq 65$ & 90 (36\%) & 17 (3I.5\%) & $73(37.2 \%)$ \\
\hline$<65$ & 160 (64\%) & 37 (68.5\%) & $123(62.8 \%)$ \\
\hline \multicolumn{4}{|l|}{ Clinical stage } \\
\hline Stage II & 40 (16\%) & 10 (I8.9\%) & 30 (15.5\%) \\
\hline Stage III & $4 \mathrm{I}(16.4 \%)$ & 9 (I7.0\%) & $32(16.0 \%)$ \\
\hline Stage IV & $169(67.6 \%)$ & 35 (64.2\%) & 134 (68.4\%) \\
\hline \multicolumn{4}{|l|}{ T stage } \\
\hline $\mathrm{T} 2$ & 20 (7.8\%) & 4 (7.5\%) & 16 (7.9\%) \\
\hline $\mathrm{T} 3$ & 65 (25.9\%) & $16(30.2 \%)$ & 49 (24.7\%) \\
\hline $\mathrm{T} 4$ & 165 (66.3\%) & 34 (62.3\%) & $|3|(67.4 \%)$ \\
\hline \multicolumn{4}{|l|}{$\mathrm{N}$ stage } \\
\hline No & 66 (26.4\%) & 16 (29.6\%) & 50 (25.5\%) \\
\hline $\mathrm{NI}$ & 88 (35\%) & 21 (38.9\%) & 67 (33.9\%) \\
\hline N2 & 79 (31.7\%) & 16 (29.6\%) & 63 (32.3\%) \\
\hline N3 & 17 (6.9\%) & I (I.9\%) & $16(8.3 \%)$ \\
\hline \multicolumn{4}{|c|}{ Concurrent chemotherapy } \\
\hline Yes & I 72 (67.9\%) & 40 (74. I\%) & 132 (67.3\%) \\
\hline No & 78 (32.1\%) & 14 (25.9\%) & 64 (32.7\%) \\
\hline \multicolumn{4}{|c|}{ Simultaneously integrated boost } \\
\hline Yes & $146(58.1 \%)$ & $34(62.3 \%)$ & II 2 (56.9\%) \\
\hline No & 104 (4I.9\%) & $20(37.7 \%)$ & $84(43.1 \%)$ \\
\hline \multicolumn{4}{|l|}{ GTV } \\
\hline$\geq 32 \mathrm{~cm}^{3}$ & $130(50.2 \%)$ & $21(40.0 \%)$ & $109(53.1 \%)$ \\
\hline$<32 \mathrm{~cm}^{3}$ & $120(49.8 \%)$ & $33(60.0 \%)$ & 87 (46.9\%) \\
\hline \multicolumn{4}{|l|}{ Lesion length (cm) } \\
\hline Range & $3-27$ & $3-8.6$ & $3-27$ \\
\hline Median length & 6.5 & 4.2 & 6.5 \\
\hline \multicolumn{4}{|l|}{ Dose (Gy) } \\
\hline Range & $48-70$ & $48-66$ & $48-70$ \\
\hline Median length & 60 & 60 & 60 \\
\hline
\end{tabular}

Abbreviation: GTV, gross tumor volume.

in 145 patients who received concurrent chemotherapy and 40 patients who did not receive concurrent chemotherapy.
SD and PD were observed in 42 patients who received concurrent chemotherapy and 23 patients who did not receive concurrent chemotherapy $(P>0.05)$. The median OS of patients who received adjuvant chemotherapy and those who did not receive adjuvant chemotherapy was 22.14 and 11.33 months, respectively $(P=0.004)$; the corresponding PFS was 15.70 and 13.77 months, respectively $(P=0.052)$. $\mathrm{CR}$ and PR were observed in 57 patients who received adjuvant chemotherapy and 128 patients who did not receive adjuvant chemotherapy. SD and PD were observed in 18 patients who received adjuvant chemotherapy and 47 patients who did not receive adjuvant chemotherapy $(P>0.05)$. In addition, age, $\mathrm{T}$ stage and $\mathrm{N}$ stage were significantly associated with OS $(P<0.05)$ (Table 2$)$.

Results of multivariate analysis of OS and PFS are presented in Table 3. Age $(\mathrm{HR}=1.037, P=0.002)$, radiotherapy dose $(\mathrm{HR}=0.624, P=0.004)$ and the $\mathrm{T}$ stage of esophageal cancer $(\mathrm{HR}=1.775, P=0.011)$ had a significant impact on OS. Besides, radiotherapy dose $(\mathrm{HR}=0.714$, $P=0.008)$ and treatment with concurrent chemotherapy ( $\mathrm{HR}=0.670, P=0.029)$ were independent prognostic factors for PFS of patients with cervical and upper thoracic esophageal cancer.

\section{Treatment failure}

One hundred and thirty-eight patients developed recurrent disease, and the recurrence rate was $55.2 \%$. Local recurrence occurred in 56 patients $(22.4 \%)$, lymph node recurrence occurred in $26(10.4 \%)$ patients and distant metastasis occurred in $31(12.4 \%)$ patients. The proportion of patients with local recurrence after IMRT was higher than other patterns of recurrence $(P<0.05)$. The median OS of patients with lymph node recurrence, local recurrence and distant metastasis was $30.62,16.92$ and 15.84 months, respectively. OS of patients with lymph node recurrence was significantly longer than that of patients with local recurrence $(P=0.038)$. OS of patients with lymph node recurrence was significantly longer than that of patients with distant metastasis $(P=0.033)$; however, there was no significant difference between OS of patients with local recurrence and those with distant metastasis $(P=0.79)$ (Table 4).

\section{Toxicity}

The acute radiotherapeutic toxicity among all patients was evaluated during treatment and during 1st 3-month postradiotherapy, and the most serious acute responses to radiotherapy were recorded. The incidence and severity 
A

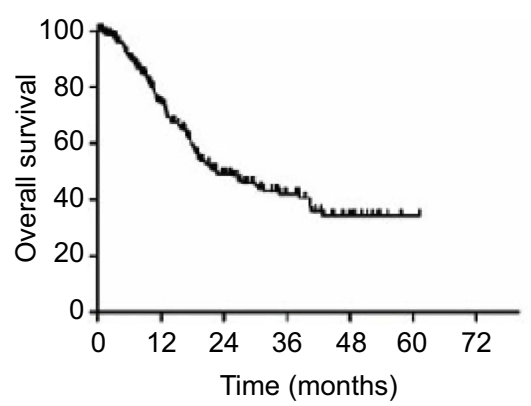

B

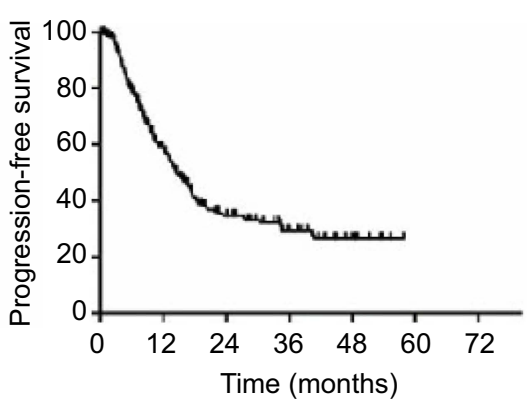

Figure I Survival curves of 250 patients of cervical and upper esophageal carcinoma treated with IMRT. (A) The overall survival of patients; (B) the progression-free survival of patients.

A

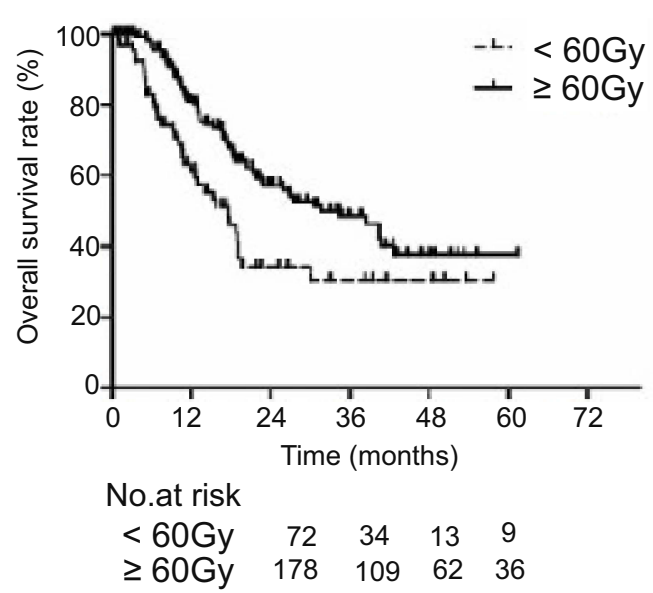

B

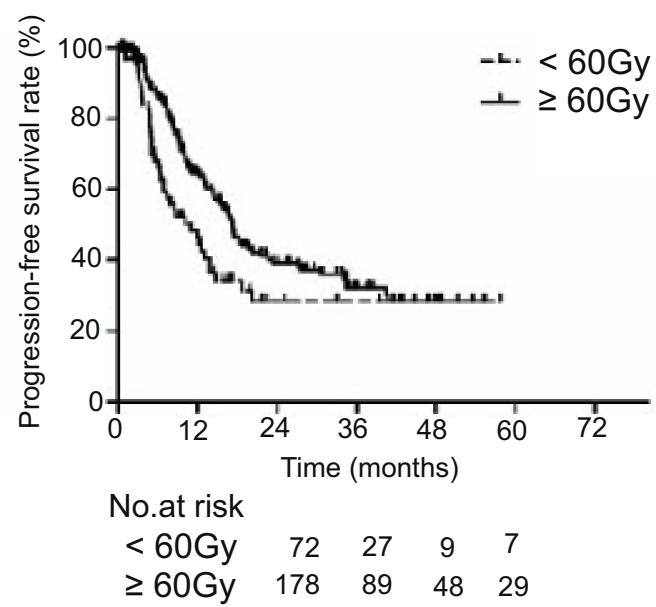

Figure 2 Comparison of survival curves of patients with different radiotherapy dose. survival of patients with different target dose.

of acute toxicity are shown in Table 5. Patients with neck and upper thoracic esophageal cancer who received IMRT experienced mostly grade 1-2 adverse reactions. Among these, grade 1-2 radiation esophagitis and radiation pneumonitis occurred in 61 patients $(24.4 \%)$ and 25 patients (10.0\%), respectively; 112 (44.8\%) patients experienced grade 1-2 myelosuppression. Grade 3-4 acute radiation esophagitis and radiation pneumonitis occurred in 17 $(6.8 \%)$ and $7(2.8 \%)$ patients, respectively, while 7 (2.8\%) patients experienced grade 3-4 myelosuppression. All patients who experienced adverse radiotherapy reactions recovered with appropriate treatment. No patients needed esophageal dilation after treatment.

\section{Discussion}

Cervical and upper thoracic esophageal cancer accounts for approximately $15 \%$ of esophageal cancer. ${ }^{11}$ Because of the complex anatomical structures around the cervical and upper thoracic segments (such as trachea, jugular vein, aorta and their branches), mortality of patients with cervical and upper thoracic esophageal cancer is still high and postoperative complications are liable to occur after surgery alone. In addition, several studies have shown that the 5 -year OS rate of patients with cervical esophageal cancer after surgery is only $12-27 \%$ and the postoperative mortality rate is $6-20 \%{ }^{3,12,13}$ Cervical esophageal cancer often involves the upper thoracic segment of esophagus and cervical esophageal cancer is often accompanied by upper thoracic esophageal cancer; thus, the treatment methods for these tumors are also very similar.

Surgery alone has been reported ineffective in patients with cervical esophageal cancer. Contrastively, radiotherapy and radiotherapy combined with surgery have better therapeutic efficacy. ${ }^{9,14}$ In our study, 54 patients $(24.5 \%)$ had 
Table 2 Univariate analysis of 250 patients of cervical and upper esophageal carcinoma treated with IMRT

\begin{tabular}{|c|c|c|c|c|c|c|c|c|}
\hline \multirow[t]{2}{*}{ Clinical characteristics } & \multirow[t]{2}{*}{ Median OS (months) } & \multicolumn{2}{|c|}{$\begin{array}{l}\text { Overall survival } \\
\text { rate }\end{array}$} & \multirow[t]{2}{*}{$P$-value } & \multirow[t]{2}{*}{$\begin{array}{l}\text { Median PFS } \\
\text { (months) }\end{array}$} & \multicolumn{2}{|c|}{$\begin{array}{l}\text { Progression-free } \\
\text { survival rate }\end{array}$} & \multirow[t]{2}{*}{$P$-value } \\
\hline & & I year & 3 year & & & I year & 3 year & \\
\hline Age (years) & & & & 0.002 & & & & 0.696 \\
\hline$\geq 65$ & 42.71 & 0.77 & 0.56 & & 16.59 & 0.63 & 0.24 & \\
\hline$<65$ & 18.96 & 0.69 & 0.28 & & 14.39 & 0.69 & 0.32 & \\
\hline Sex & & & & 0.586 & & & & 0.209 \\
\hline Male & 21.32 & 0.73 & 0.43 & & 18.66 & 0.57 & 0.27 & \\
\hline Female & 21.32 & 0.78 & 0.39 & & 18.66 & 0.65 & 0.37 & \\
\hline $\operatorname{GTV}\left(\mathrm{cm}^{3}\right)$ & & & & 0.046 & & & & 0.108 \\
\hline$\geq 32$ & 20.46 & 0.64 & 0.37 & & 10.94 & 0.49 & 0.29 & \\
\hline$<32$ & 40.44 & 0.83 & 0.48 & & 16.70 & 0.66 & 0.36 & \\
\hline Dose & & & & 0.002 & & & & 0.018 \\
\hline$\geq 60$ Gy & 34.46 & 0.81 & 0.49 & & 17.28 & 0.64 & 0.32 & \\
\hline$<60 \mathrm{~Gy}$ & 17.64 & 0.61 & 0.30 & & 10.94 & 0.48 & 0.28 & \\
\hline Concurrent chemotherapy & & & & 0.013 & & & & 0.039 \\
\hline Yes & 30.62 & 0.79 & 0.47 & & 15.84 & 0.63 & 0.35 & \\
\hline No & 18.60 & 0.65 & 0.30 & & 10.94 & 0.49 & 0.18 & \\
\hline Adjuvant chemotherapy & & & & 0.004 & & & & 0.052 \\
\hline Yes & 22.14 & 0.72 & 0.42 & & 15.70 & 0.60 & 0.34 & \\
\hline No & 11.33 & 0.75 & 0.42 & & 13.77 & 0.59 & 0.29 & \\
\hline T stage & & & & 0.012 & & & & 0.232 \\
\hline $\mathrm{T} 2$ & 40.48 & 0.81 & 0.53 & & 34.20 & 0.70 & 0.38 & \\
\hline T3 & 38.41 & 0.86 & 0.50 & & 17.45 & 0.67 & 0.29 & \\
\hline $\mathrm{T} 4$ & 18.76 & 0.69 & 0.36 & & 13.14 & 0.54 & 0.29 & \\
\hline$N$ stage & & & & 0.002 & & & & 0.089 \\
\hline No & 38.41 & 0.83 & 0.50 & & 16.72 & 0.65 & 0.31 & \\
\hline $\mathrm{NI}$ & 31.70 & 0.77 & 0.46 & & 17.54 & 0.62 & 0.36 & \\
\hline N2 & 18.27 & 0.68 & 0.21 & & 12.03 & 0.52 & 0.22 & \\
\hline N3 & 12.58 & 0.53 & 0.13 & & 12.58 & 0.40 & 0.20 & \\
\hline Clinical stage & & & & 0.004 & & & & 0.168 \\
\hline Stage II & 38.41 & 0.86 & 0.64 & & 20.24 & $0.7 \mathrm{I}$ & 0.40 & \\
\hline Stage III & 25.82 & 0.85 & 0.42 & & 17.45 & 0.67 & 0.31 & \\
\hline Stage IV & 18.76 & 0.69 & 0.36 & & 13.14 & 0.53 & 0.29 & \\
\hline
\end{tabular}

Abbreviation: GTV, gross tumor volume.

cervical esophageal cancer. The 1-, 2- and 3-year OS rates were $75.2 \%, 46.4 \%$ and $38.7 \%$ for these patients, respectively, which were superior to that of patients who received surgery alone. ${ }^{15-17}$ In the past decade, whether radiotherapy or surgery is the better treatment for upper thoracic esophageal cancer is a hot topic. Wang et al conducted a retrospective study of 78 patients with upper thoracic esophageal cancer treated with surgery. The results showed that the median OS was 13.1 months, and the 1-, 3- and 5year OS rates were $53.9 \%, 28.7 \%$ and $21.4 \%$, respectively; the recurrence rate was $59 \% .{ }^{18}$ Manshanden et al also reported the median OS of 10.0 months for patients with upper thoracic esophageal cancer. ${ }^{19}$ However, Zhu et al evaluated the clinical effect of IMRT in patients with upper thoracic esophageal cancer. They reported that the 1-, 3and 5-year survival rates were $65 \%, 50 \%$ and $35 \%$, respectively. ${ }^{20}$ These studies suggested that IMRT might have superior clinical efficacy in patients with upper thoracic esophageal cancer than surgery alone. ${ }^{21}$ In our study, 196 patients with upper thoracic esophageal cancer $(78.4 \%$ ) were 
Table 3 Multivariate analysis of 250 patients of cervical and upper esophageal carcinoma treated with IMRT

\begin{tabular}{|c|c|c|c|c|c|c|}
\hline \multirow[t]{2}{*}{ Clinical characteristics } & \multicolumn{3}{|l|}{ Median OS } & \multicolumn{3}{|l|}{ Median PFS } \\
\hline & $95 \% \mathrm{Cl}$ & HR & $P$-value & $95 \% \mathrm{Cl}$ & HR & $P$-value \\
\hline $\begin{array}{l}\text { Age (years) } \\
\quad \geq 65 \\
\quad<65\end{array}$ & $1.013-1.062$ & 1.037 & 0.002 & & & \\
\hline $\begin{array}{l}\text { Dose } \\
\qquad 60 \mathrm{~Gy} \\
\geq 60 \mathrm{~Gy}\end{array}$ & $0.455-0.857$ & 0.624 & 0.004 & $0.556-0.916$ & 0.714 & 0.008 \\
\hline $\begin{array}{l}\text { GTV }\left(\mathrm{cm}^{3}\right) \\
\quad \geq 32 \mathrm{~cm}^{3} \\
<32 \mathrm{~cm}^{3}\end{array}$ & $0.688-1.754$ & 1.098 & 0.694 & & & \\
\hline $\begin{array}{l}\text { Concurrent chemotherapy } \\
\text { Yes } \\
\text { No }\end{array}$ & $0.512-1.490$ & 0.874 & 0.620 & $0.467-0.960$ & 0.670 & 0.029 \\
\hline $\begin{array}{l}\text { Adjuvant chemotherapy } \\
\text { Yes } \\
\text { No }\end{array}$ & $0.437-1.157$ & 0.711 & 0.170 & & & \\
\hline T stage & I.I40-2.763 & 1.775 & 0.011 & & & \\
\hline $\mathrm{N}$ stage & $0.982-|.65|$ & 1.273 & 0.069 & & & \\
\hline
\end{tabular}

Abbreviation: GTV, gross tumor volume.

Table 4 Recurrence of 250 patients of cervical and upper esophageal carcinoma treated with IMRT

\begin{tabular}{|l|l|l|l|l|l|}
\hline & Median OS (months) & I-year survival rate & 2-year survival rate & 3-year survival rate & P-value \\
\hline Overall recurrence & 15.34 & $61.4 \%$ & $26.6 \%$ & $16.6 \%$ & \\
Local recurrence & 16.92 & $73.7 \%$ & $27.5 \%$ & $17.9 \%$ & 0.012 \\
Lymph node recurrence & 30.62 & $78.2 \%$ & $56.5 \%$ & $43.0 \%$ & $11.7 \%$ \\
Distant metastasis & 15.84 & $60.1 \%$ & $28 \%$ & & \\
\hline
\end{tabular}

Table 5 Radiation-related complications of 250 patients of cervical and upper esophageal carcinoma treated with IMRT

\begin{tabular}{|l|l|l|l|l|l|}
\hline Toxicity & Grade 0 (\%) & Grade I (\%) & Grade 2 (\%) & Grade 3 (\%) & Grade 4 (\%) \\
\hline $\begin{array}{l}\text { Hematologic toxicity } \\
\text { Leukocytopenia }\end{array}$ & $139(55.6 \%)$ & $61(24.4 \%)$ & $30(12 \%)$ & $6(2.4 \%)$ & \\
Hypohemoglobin & $123(49.2 \%)$ & $98(39.2 \%)$ & $14(5.6 \%)$ & $2(0.8 \%)$ & $1(0.4 \%)$ \\
Thrombocytopenia & $185(74 \%)$ & $40(16.0 \%)$ & $10(4 \%)$ & $2(0.8 \%)$ & 0 \\
Radioactive esophagitis & $159(63.6 \%)$ & $25(10.0 \%)$ & $36(14.4 \%)$ & $15(6 \%)$ & 0 \\
Radiation pneumonia & $205(82 \%)$ & $22(8.8 \%)$ & $3(1.2 \%)$ & $7(2.8 \%)$ & $2(0.8 \%)$ \\
\hline
\end{tabular}

treated with IMRT. The median OS was 25.82 months, and the 1-, 2- and 3-year survival rates were $74.2 \%, 50.1 \%$ and $41.1 \%$, respectively. The OS of patients treated by IMRT in our study was better than that of patients treated by surgery in Wang's study. ${ }^{18}$ In addition, patients with upper thoracic esophageal cancer who received surgery had a high rate of complication, such as bleeding and pneumonia, and experienced a high risk of death. ${ }^{22}$ While in our study, there is a greater incidence of grade I-II radiotherapy toxicity in patients, but treatment-related death did not happen. Compared with surgical treatment, IMRT had the advantage of a shorter duration of therapy and fewer side effects. 
Table 6 Results of radiotherapy and surgery for cervical and upper thoracic esophageal

\begin{tabular}{|c|c|c|c|c|c|c|c|}
\hline \multirow[t]{2}{*}{ Authors } & \multirow[t]{2}{*}{ Total no. of cases } & \multirow[t]{2}{*}{ Location } & \multirow[t]{2}{*}{ Treatment } & \multirow{2}{*}{$\begin{array}{l}\text { Median overall } \\
\text { survival (months) }\end{array}$} & \multicolumn{3}{|c|}{ Overall survival rate } \\
\hline & & & & & I year & 2 year & 3 year \\
\hline Wang et al ${ }^{18}$ & 78 & Upper & Surgery & 13.1 & $53.9 \%$ & - & $28.7 \%$ \\
\hline Zhu et $\mathrm{al}^{20}$ & 30 & Upper & IMRT & - & $65.0 \%$ & $50.0 \%$ & $35.0 \%$ \\
\hline Manshanden et al ${ }^{19}$ & 30 & Upper & Surgery & 10.0 & - & - & - \\
\hline Esmati et $\mathrm{al}^{21}$ & 40 & Cervical and upper & 3DCRT & 19.2 & $76.0 \%$ & $38.0 \%$ & $16.0 \%$ \\
\hline Li et al $^{9}$ & 92 & Cervical & 3D/IMRT & 36.0 & $88.0 \%$ & $66.3 \%$ & $49.8 \%$ \\
\hline Cao et $\mathrm{al}^{17}$ & 27 & Cervical & Surgery & - & - & $50.7 \%$ & - \\
\hline Present study & 54 & cervical & IMRT & 20.37 & $75.2 \%$ & $46.4 \%$ & $38.7 \%$ \\
\hline Present study & 196 & Upper & IMRT & 25.8 & $74.2 \%$ & $50.1 \%$ & $41.1 \%$ \\
\hline
\end{tabular}

Therefore, IMRT is an effective treatment for patients with upper thoracic esophageal cancer (Table 6).

Several studies have reported the superiority of IMRT over other radiotherapeutic modalities for treatment of esophageal cancer. ${ }^{23,24}$ However, most of these studies pertained to patients with thoracic middle-lower segment esophageal carcinoma, and the clinical outcomes of IMRT in patients with esophageal cancer in the cervical and upper thoracic segments are not well characterized. Lachlan et al compared the efficacy of different radiotherapy methods for cervical esophageal cancer. Their results showed better 2-year and 5-year survival rates of patients with cervical esophageal cancer after IMRT (53\% and $43 \%$, respectively) as compared to that after 2-dimensional radiotherapy (33\% and $14 \%$, respectively) or $3-$ dimensional conformal radiotherapy (CRT) $(43 \%$ and $22 \%$, respectively). ${ }^{25}$ In our previous study, the survival rates of patients with upper thoracic esophageal cancer after IMRT were higher than those of their counterparts treated with CRT. ${ }^{26}$ Zhang et al compared the dose distribution of CRT and IMRT in patients with upper thoracic esophageal cancer. They found that the dose distribution of IMRT was more accurate compared with CRT and that IMRT reduced the dose of spinal cord and lung tissue, which reduced the risk of complications. ${ }^{27}$

Radiotherapy dose is an important prognostic factor for patients with esophageal cancer. Zhu et al compared the effects of different radiotherapy doses on the treatment of esophageal cancer; the results showed that after IMRT, patients in the high-dose group $(2.13 \mathrm{~Gy} / 30 \mathrm{f})$ were significantly more likely to achieve complete remission (CR) than patients in the conventional dose group (2 Gy/30f). In addition, the 1-, 2- and 3-year PFS rates in the high-dose group $(60 \%, 40 \%$ and $25 \%$, respectively) were significantly higher than those in the conventional dose group $\left(41.7 \%, 25 \%\right.$ and $8.3 \%$, respectively). ${ }^{28}$ In our study, radiotherapy dose was one of the important prognostic factors in patients with cervical and upper thoracic esophageal cancer.

Concurrent chemotherapy also plays an important role in the radiotherapy of patients with esophageal cancer. Zhao et al conducted a retrospective study of 122 patients with esophageal squamous cell carcinoma; among these, 52 patients received concurrent chemoradiotherapy based on platinum and fluorouracil and 70 patients received radiotherapy alone. The OS and PFS in the concurrent chemoradiotherapy group (15.3 and 24.6 months, respectively) were significantly longer than that in the radiotherapy group (10.6 and 19.4 months, respectively) $(P<0.05) .{ }^{29}$ In this study, 172 patients underwent concurrent chemotherapy; the OS of patients who received concurrent chemoradiotherapy and those who received radiotherapy alone was 30.62 and 18.60 months, respectively. The results showed that concurrent chemoradiotherapy conferred a significant survival benefit in patients with neck and upper thoracic esophageal cancer $(P<0.05)$.

Zhong et al found a significant difference between the 5 -year survival rates of patients with stage II and III esophageal cancer $(P<0.05)$; in addition, both $\mathrm{T}$ stage and $\mathrm{N}$ stage were associated with prognosis of patients. ${ }^{30}$ This study also found that the survival time of patients with stage II disease was significantly longer than that of patients with stage IV disease $(P<0.05)$.

This retrospective study has limitations. Late toxicity, such as swallowing ability, quality of voice of patients and so on, was collected in part of patients.

\section{Conclusion}

Our results indicated that IMRT had clinical benefit for patients with cervical and upper thoracic esophageal 
squamous cell carcinoma. Age, radiotherapy dose and the $\mathrm{T}$ stages of esophageal cancer had a significant impact on OS. And radiotherapy dose and treatment with concurrent chemotherapy were independent prognostic factors for PFS of patients with cervical and upper thoracic esophageal cancer.

\section{Ethics approval and informed consent}

All procedures performed in studies involving human participants were in accordance with the ethical standards of the Institutional Review Board (IRB) of Tianjin Medical University Cancer Institute \& Hospital (TCIH) and with the 1975 Declaration of Helsinki and its later amendments or comparable ethical standards. Written informed consent was obtained from all individual participants included in the study.

\section{Acknowledgment}

The authors thank the staff of the Tianjin Cancer Hospital and all of the patients who were associated with this study.

\section{Author contributions}

All authors contributed to data analysis, drafting or revising the article, gave final approval of the version to be published and agree to be accountable for all aspects of the work.

\section{Disclosure}

The authors report no conflicts of interest in this work.

\section{References}

1. Jemal A, Bray F, Center MM, et al. Global cancer statistics. $C A$ Cancer J Clin. 2011;61(2):69-90. doi:10.3322/caac.20107

2. Lee DJ, Harris A, Gillette A, Munoz L, Kashima H. Carcinoma of the cervical esophagus: diagnosis, management, and results. South Med J. 1984;77(11):1365-1367. doi:10.1097/00007611-198411000-00004

3. Gong Y, Wang S, Zhou L, et al. Dosimetric comparison using different multileaf collimeters in intensity-modulated radiotherapy for upper thoracic esophageal cancer. Radiat Oncol. 2010;5:65. doi:10.1186/ 1748-717X-5-65

4. Huang SH, Lockwood G, Brierley J, et al. Effect of concurrent highdose cisplatin chemotherapy and conformal radiotherapy on cervical esophageal cancer survival. Int J Radiat Oncol Biol Phys. 2008;71 (3):735-740. doi:10.1016/j.jirobp.2007.10.022

5. Uno T, Isobe K, Kawakami $\mathrm{H}$, et al. Concurrent chemoradiation for patients with squamous cell carcinoma of the cervical esophagus. Dis Esophagus. 2007;20(1):12-18. doi:10.1111/j.1442-2050.2007.00632.x

6. Wang HW, Chu PY, Kuo KT, et al. A reappraisal of surgical management for squamous cell carcinoma in the pharyngoesophageal junction. J Surg Oncol. 2006;93(6):468-476. doi:10.1002/jso.20472

7. Laterza E, Mosciaro O, Urso US, Inaspettato G, Cordiano C. Primary carcinoma of the hypopharynx and cervical esophagus: evolution of surgical therapy. Hepatogastroenterology. 1994;41(3):278-282.
8. Du XX, Yu R, Wang ZF, et al. Outcomes and prognostic factors for patients with cervical esophageal cancer undergoing definitive radiotherapy or chemoradiotherapy. Bosn J Basic Med Sci. 2019;19 (2):186-194. doi:10.17305/bjbms.2019.3873

9. Li HX, Liu J, Cheng Y, Liu MN, Fang WT, Lv CX. Concurrent chemoradiotherapy for cervical esophageal squamous cell carcinoma: treatment results from a prospective observational study. Dis Esophagus. 2018;31:5. doi:10.1093/dote/dox144

10. Eisenhauer EA, Therasse P, Bogaerts J, et al. New response evaluation criteria in solid tumours: revised RECIST guideline (version 1.1). Eur $J$ Cancer. 2009;45(2):228-247. doi:10.1016/j. ejca.2008.10.026

11. Bai W, Zhou Z, Zhen C, et al. Long-term efficacy of 159 cases of cervical and upper esophageal carcinoma treated with intensitymodulated radiotherapy. Chin J Radiol Med Prot. 2016;36(1):2834. doi:10.3760/cma.j.issn.0254-5098.2016.01.005

12. Kumabe A, Zenda S, Motegi A, et al. Long-term clinical results of concurrent chemoradiotherapy for patients with cervical esophageal squamous cell carcinoma. Anticancer Res. 2017;37(9):5039-5044. doi:10.21873/anticanres.11919

13. Mendenhall WM, Sombeck MD, Parsons JT, et al. Management of cervical esophageal carcinoma. Semin Radiat Oncol. 1994;4(3):179191. doi:10.1053/SRAO00400179

14. Grass GD, Cooper SL, Armeson K, Garrett-Mayer E, Sharma A. Cervical esophageal cancer: a population-based study. Head Neck. 2015;37(6):808-814. doi:10.1002/hed.23678

15. Duan X, Zhao E, Cong T, Shen H, Xiao S, Qin Y. [Surgical management of cervical esophageal carcinoma in 16 cases]. Lin Chung Er Bi Yan Hou Tou Jing Wai Ke Za Zhi. 2013;27(24):1347-1351.

16. Daiko H, Hayashi R, Saikawa M, et al. Surgical management of carcinoma of the cervical esophagus. J Surg Oncol. 2007;96 (2):166-172. doi:10.1002/jso.20795

17. Cao CN, Luo JW, Gao L, et al. Primary radiotherapy compared with primary surgery in cervical esophageal cancer. JAMA Otolaryngol Head Neck Surg. 2014;140(10):918-926. doi:10.1001/jamaoto.2014.2013

18. Wang HW, Kuo KT, Wu YC, et al. Surgical results of upper thoracic esophageal carcinoma. J Chin Med Assoc. 2004;67(9):447-457. doi:10.1111/j.1464-410X.2006.06272.x

19. Manshanden CG, Hulscher JBF, Hovius M, Fockens P, van Lanschot JJB, Obertop H. Limited resection for carcinoma of the upper thoracic oesophagus is not a realistic option. Eur J Surg Oncol (EJSO). 2000;26(6):561-566. doi:10.1053/ejso.2000.0947

20. Zhu WG, Yu CH, Han JH, Li T, Zhou XL, Tao GZ. Feasibility and shortterm efficacy of simplified intensity-modulated radiotherapy and concurrent chemotherapy for neck and upper thoracic esophageal carcinoma. Chin J Cancer. 2009;28(12):1265-1269. doi:10.5732/cjc.009.10215

21. Esmati E, Maddah SA, Ghalehtaki R, et al. Outcomes of definitive chemoradiotherapy for cervical and upper thoracic esophageal cancers: a single-institution experience of a rare cancer. J Gastrointest Cancer. 2018. doi:10.1007/s12029-018-0081-8

22. Yu L, Wu JX, Gao YS, Li JY, Zhang YF, Ke J. Pros and cons of the gasless laparoscopic transhiatal esophagectomy for upper esophageal carcinoma. Surg Endosc. 2016;30(6):2382-2389. doi:10.1007/s00464-015-4488-z

23. Lin SH, Wang L, Myles B, et al. Propensity score-based comparison of long-term outcomes with 3-dimensional conformal radiotherapy vs intensity-modulated radiotherapy for esophageal cancer. Int $J$ Radiat Oncol Biol Phys. 2012;84(5):1078-1085. doi:10.1016/j.ijrobp.2012.02.015

24. Haefner MF, Lang K, Verma V, et al. Intensity-modulated versus 3dimensional conformal radiotherapy in the definitive treatment of esophageal cancer: comparison of outcomes and acute toxicity. Radiat Oncol. 2017;12(1):131. doi:10.1186/s13014-017-0863-3

25. McDowell LJ, Huang SH, Xu W, et al. Effect of intensity modulated radiation therapy with concurrent chemotherapy on survival for patients with cervical esophageal carcinoma. Int $J$ Radiat Oncol Biol Phys. 2017;98(1):186-195. doi:10.1016/j.ijrobp.2017.0 1.003 
26. Ma JB, Song YP, Yu JM, et al. Feasibility of involved-field conformal radiotherapy for cervical and upper-thoracic esophageal cancer. Oncol Res Treat. 2011;34(11):599-604. doi:10.1159/000334194

27. Zhang WZ, Chen ZJ, Li DR, et al. [Dosimetric comparison between intensity-modulated radiotherapy and conformal radiotherapy for upper thoracic esophageal carcinoma]. Ai Zheng. 2009;28(11):11271131. doi: $10.5732 /$ cjc.008.10839

28. Zhu WG, Zhou K, Yu CH, et al. Efficacy analysis of simplified intensity-modulated radiotherapy with high or conventional dose and concurrent chemotherapy for patients with neck and upper thoracic esophageal carcinoma. Asian Pac J Cancer Prev. 2012;13(3):803-807. doi:10.7314/APJCP.2012.13.3.803
29. Zhao Q, Hu G, Xiao W, et al. Comparison of definitive chemoradiotherapy and radiotherapy alone in patients older than 75 years with locally advanced esophageal carcinoma: a retrospective cohort study. Medicine (Baltimore). 2017;96(35):e7920. doi:10.1097/MD.0000000000007920

30. Zhong H, Ma R, Gong L, et al. [Comparison of the prognostic value of the seventh and eighth edition of the AJCC esophageal cancer staging system for the patients with stage and esophageal squamous cell carcinoma]. Zhonghua Wai Ke Za Zhi. 2017;55(12):903-908. doi:10.3760/cma.j.issn.0529-5815.2017.12.006

\section{Publish your work in this journal}

Cancer Management and Research is an international, peer-reviewed open access journal focusing on cancer research and the optimal use of preventative and integrated treatment interventions to achieve improved outcomes, enhanced survival and quality of life for the cancer patient.
The manuscript management system is completely online and includes a very quick and fair peer-review system, which is all easy to use. Visit http://www.dovepress.com/testimonials.php to read real quotes from published authors. 